\title{
RACKING STRENGTH OF PAPERBOARD BASED SHEATHING MATERIALS
}

\author{
$\mathrm{Wu} \mathrm{Bi}{ }^{\mathrm{a}}$ and Douglas W. Coffin ${ }^{\mathrm{b}^{*}}$ \\ Small-scale racking testers were developed for use as a means to \\ evaluate paperboard-based sheathing materials used in framed wall- \\ construction. For the purpose of evaluating the performance of different \\ sheathing materials, the tester provides an economic alternative to \\ standard full-scale racking tests. In addition, results from testing provide \\ practical insight into the racking response of framed and sheathed walls. \\ The load-deformation responses of three commercial sheathing boards \\ were measured, and initial racking stiffness and racking strength were \\ proposed as parameters for characterizing the board. The racking test \\ results showed that the initial paperboard racking stiffness correlated to \\ elastic modulus and caliper, but the response was insensitive to \\ paperboard orientation or test dimensions. Observations and results \\ showed that both panel buckling and paperboard cutting at the staples \\ affected the racking response, but the dominating factor influencing the \\ racking response appears to be load transfer through the staples.
}

Keywords: Racking, Paperboard, Sheathing, Strength, and Stiffness

Contact information: a: Department. of Chem. Eng., Georgia Institute of Technology, 311 Ferst Drive, NW, Atlanta, GA 30332; b: Department of Paper and Chemical Engineering, Miami University, Oxford, OH 45056; *Corresponding author: coffindw@muohio.edu

\section{INTRODUCTION}

The walls of buildings must have adequate strength and rigidity to resist wind and seismic forces. Sheathing materials are normally applied to one or both faces of wall framing to limit in-plane shear distortion of the wall. This shear deformation is called racking. Common sheathing materials used in home construction include plywood, gypsum board, and flakeboard, which have thickness on the order of one half inch. Paperbased sheathing materials are now being produced for prefabricated homes. The caliper of these materials is less than one eighth of an inch. Currently, the racking strength of many of these paper-based materials is inadequate for general home construction, but if the racking strength were improved, these materials could be applied to other building applications.

Wall-racking tests are used to evaluate sheathing materials racking stiffness and strength and certify materials for use in construction. Standard procedures such as ASTM E72, and TAPPI T1005 cm-83 are routinely used to measure the racking strength of framed and sheathed walls $(2.4$ by $2.4 \mathrm{~m}$, or 8 by $8 \mathrm{ft})$. Although, the sheathing materials are the main contributor to racking strength and stiffness, the rigid wood frame also adds to the strength and stiffness. According to ASTM E72, at least two or three runs with new testing arrangements should be done for each test. New identical frames built by the 
specified wood species with the same average density should be used for each racking test run. Full-scale wall racking tests are expensive and time-consuming to run, except for the purpose of qualifying a board. For product development, there is a need for a more convenient and less expensive test that could be used to evaluate the potential racking strength of different paperboards and fasteners.

One simplified test previously used to help evaluate sheathing materials is the lateral nail resistance test. The lateral nail resistance test according to ASTM D1037 measures the resistance of a nail to lateral movement through a board. The relationship between the racking strength and lateral nail resistance was investigated for applications with relatively thick sheathing materials, such as fiberboards, gypsum boards, and flakeboards, using both linear models (Neisel and Guerrera 1956, Neisel 1958, Welsch 1963, Tuomi and Gromala 1977, Price and Gromala 1980) and a general nonlinear energy-based approach (McCutcheon 1985). None of those models provided good predictions of racking strength because the response of the nail in the resistance test was not the same as that in the racking test. For paperboard, staples are typically used instead of nails, and the response may be different.

Small-scale wall racking tests have been utilized to evaluate sheathing materials and predict full-scale wall racking behaviors (Tuomi and Gromala 1977, Price and Gromala 1980, McCutcheon 1985, Patton-Mallory et al. 1985). The work of McCutcheon (1985) and Patton-Mallory et al. (1985) suggest that it is possible to predict full-scale wall racking behavior by small-scale racking tests. McCutcheon's (1985) work also found that a small-scale racking test yielded a more reliable prediction than the nail resistance test (Patton-Mallory et al. 1985). Currently no small-scale racking test standard is available.

For our work, we were interested in understanding how changes in the paperboard used to produce the sheathing could affect the racking strength. We were not seeking a prediction of racking strength but a method to evaluate racking strength potential. Thus, a small-scale tester that puts the paper into a global mode of in-plane shear deformation seemed appropriate. With traditional sheathing materials, in-plane shear deformation and cutting from the nails will dominate the racking response. Since the paper-based materials are thin, we expected that buckling of the board also impacts the racking response. Thus, this was considered in the design of the racking tester.

Two simplified small-scale racking testers $[0.406 \times 0.406 \mathrm{~m}(16 \times 16 \mathrm{in})$, and $0.813 \times 0.813 \mathrm{~m}(32 \times 32 \mathrm{in})]$ were designed, built, and evaluated. The racking responses of three commercial paperboards were then evaluated. Both the effects of buckling and cutting due to the staples were investigated. Paperboard cutting at the staples appeared to be significant, so a staple resistance test was developed and the effects of paperboard staple cutting on racking stiffness and racking strength were evaluated. In the following, the developed methods are described and some results are presented. 


\section{EXPERIMENTAL}

\section{Materials}

Three commercial paperboards were labeled as A, B, and C. The paperboard was cut into $0.406 \mathrm{~m}$ (16in) or $0.813 \mathrm{~m}$ (32in) squares and conditioned at a relative humidity of $50 \%$ and temperature of $23{ }^{\circ} \mathrm{C}$ for at least one week before testing. Wood inserts used in the racking test frame were also conditioned at the same temperature and humidity for more than one week. The pertinent properties of the paperboard were determined using the methods described below and are given in Table 1.

Moisture content was determined for five samples of each paperboard type, using samples with dimensions of $0.127 \times 0.203 \mathrm{~m}(5.0 \times 8.0 \mathrm{in})$. Both the initial mass and the oven-dry mass were determined. The oven-dried mass was determined by placing samples in a chamber at $103^{\circ} \mathrm{C}$ until the mass reached equilibrium. Samples were cooled in a desiccator. For grammage, five samples having dimensions of $0.127 \times 0.254 \mathrm{~m}$ $(5.0 \times 10.0 \mathrm{in})$ were cut, and the mass of each sample was determined. Mass for both moisture content and grammage was determined with the use of an analytic balance. Paperboard caliper for each of the five grammage specimens was measured with a dial caliper gage. A total of 12 measurements taken around the edges with three readings per edge were recorded and the average was computed. For elastic modulus, $10 \mathrm{MD}$ and 10 CD samples (width: $12.7 \mathrm{~mm}$ (0.5in); length: $0.20 \mathrm{~m}$ (8.0in)) for each paperboard grade were used for tensile tests, using an Instron 3344 series EM Test Instrument with clamp length of $152 \mathrm{~mm}$ with the general loading speed $2.54 \mathrm{~mm} / \mathrm{min}$. Some additional tests were done with the same loading speed as in staple resistance tests, $25.4 \mathrm{~mm} / \mathrm{min}$. Elastic modulus multiplied by sample thickness was determined from the maximum slope of the load per unit width versus strain.

The results given in Table 1 show that both caliper and basis weight increase as ranked from $\mathrm{A}$ to $\mathrm{B}$ to $\mathrm{C}$. The moisture contents of three paperboards are in the range of $8-9 \%$. The measured elastic moduli $(\mathrm{KN} / \mathrm{m})$ are given as stiffness per unit width or engineering elastic modulus multiplied by caliper. The elastic modulus of board A was about $20-25 \%$ lower in MD and 10-15\% lower in $\mathrm{CD}$ than that of $\mathrm{B}$ and $\mathrm{C}$. There are no large differences between boards $\mathrm{B}$ and $\mathrm{C}$ for both directionality and geometric mean modulus $\left(\sqrt{E_{M D} E_{C D}} \times t\right)$.

\section{Small-Scale Racking Testers}

The small-scale racking testers were designed to induce in-plane shear in the panel, but allow for fastening and panel widths similar to that in standard racking tests and actual house framing. The apparatus as shown in Fig. 1, consists of a hinged metal frame with wood inserts cut from $2 \times 4$ lumber and is essentially a picture-frame shear test. The sheathing was fastened to the frame with staples. The frame is attached to an Instron 1122 universal tester. The diagonal load and deformation in the tensile direction are recorded and used to evaluate the racking response. The stated load limit for the universal tester is a force of $4448 \mathrm{~N}$ (1000lb), but in several tests we used a maximum load closer to $5783 \mathrm{~N}(1300 \mathrm{lb})$. The load cell has a range of $22200 \mathrm{~N}(5000 \mathrm{lb})$. The racking test has the following unique features: (1) free rotation of the metal frame at all four corners, (2) replaceable wood-studs inserted in rigid U-shaped metal frames, allowing for multiple 
tests before stud replacement, and (3) the optional use of a middle wooden stud at the center of one span in the 32-inch racking tester. To eliminate the need for the paperboard to accommodate the large deformation at the corners, the corners of the sheathing sample are cut off before testing. Figure 2 shows a close-up of the hinged corners of the frame, in which a metal pin was used to hold the corner together, yet allow free rotation.

Table 1: Properties of three grades of paperboards

\begin{tabular}{|c|c|c|c|c|c|c|c|}
\hline \multirow{2}{*}{\multicolumn{2}{|c|}{ Paperboard }} & \multicolumn{2}{|c|}{ (A) } & \multicolumn{2}{|c|}{ (B) } & \multicolumn{2}{|c|}{ (C) } \\
\hline & & Mean & S.D. & Mean & S.D. & Mean & S.D. \\
\hline \multicolumn{2}{|c|}{ Basis Weight $\left(\mathrm{g} / \mathrm{m}^{2}\right)$} & 1,390 & 20 & 1,810 & 10 & 3,020 & 10 \\
\hline \multicolumn{2}{|c|}{ Caliper (t: mm) } & 1.84 & 0.02 & 2.45 & 0.03 & 3.18 & 0.02 \\
\hline \multicolumn{2}{|c|}{ Moisture Content (\%) } & 8.5 & 0.1 & 8.2 & 0.2 & 8.7 & 0.1 \\
\hline \multirow{2}{*}{$\begin{array}{l}\text { Elastic } \\
\text { Modulus }\end{array}$} & Ratio: $\mathrm{E}_{\mathrm{MD}} / \mathrm{E}_{\mathrm{CD}}$ & 2.6 & & 2.9 & & 3.0 & \\
\hline & $\begin{array}{l}\sqrt{E_{M D} E_{C D}} \times t \\
(\mathrm{kN} / \mathrm{m})\end{array}$ & 3150 & 150 & 3800 & 200 & 3900 & 200 \\
\hline
\end{tabular}

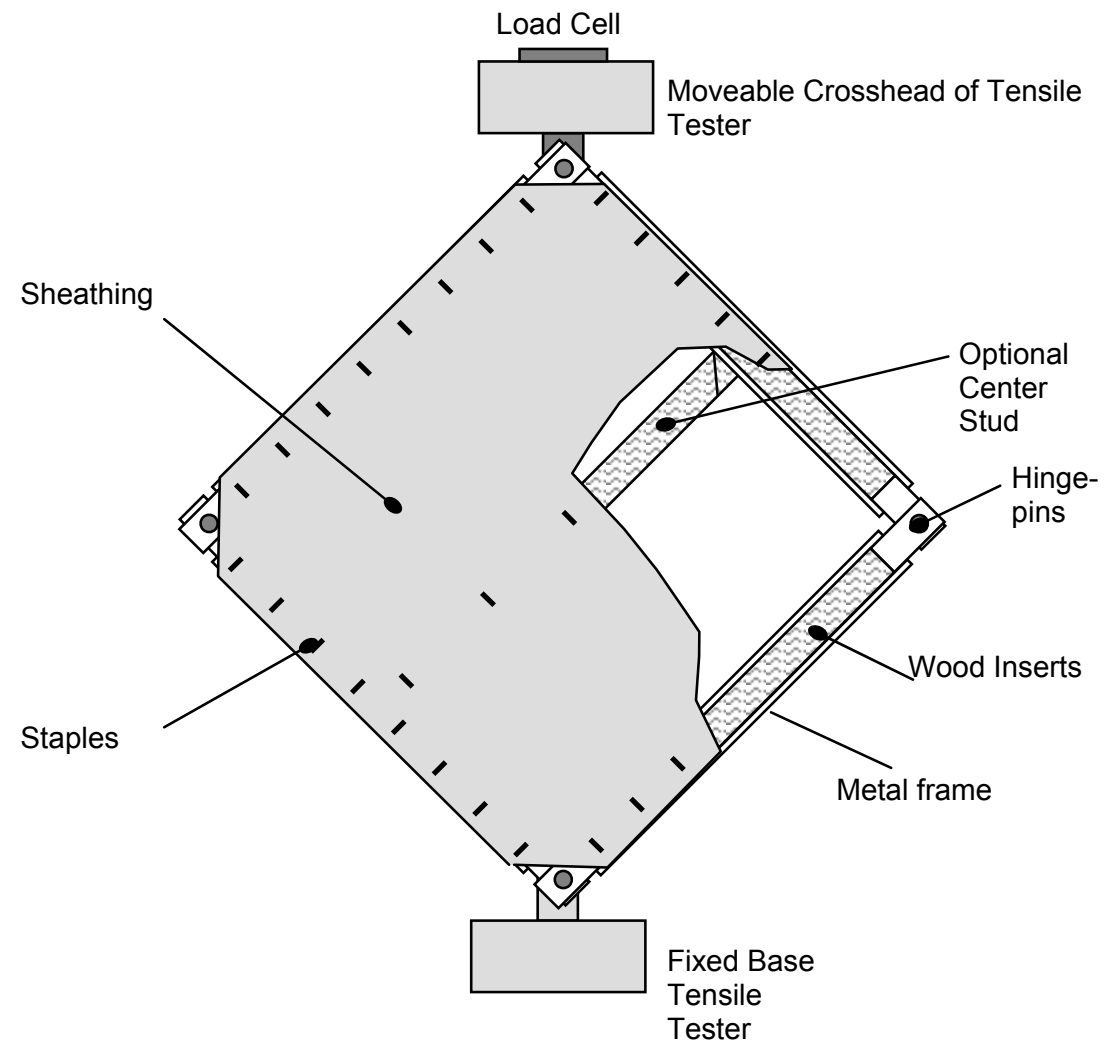

Fig. 1. Designed small-scale test system (left) and the metal frame (right). Shown for 32-inch tester with optional middle stud. 


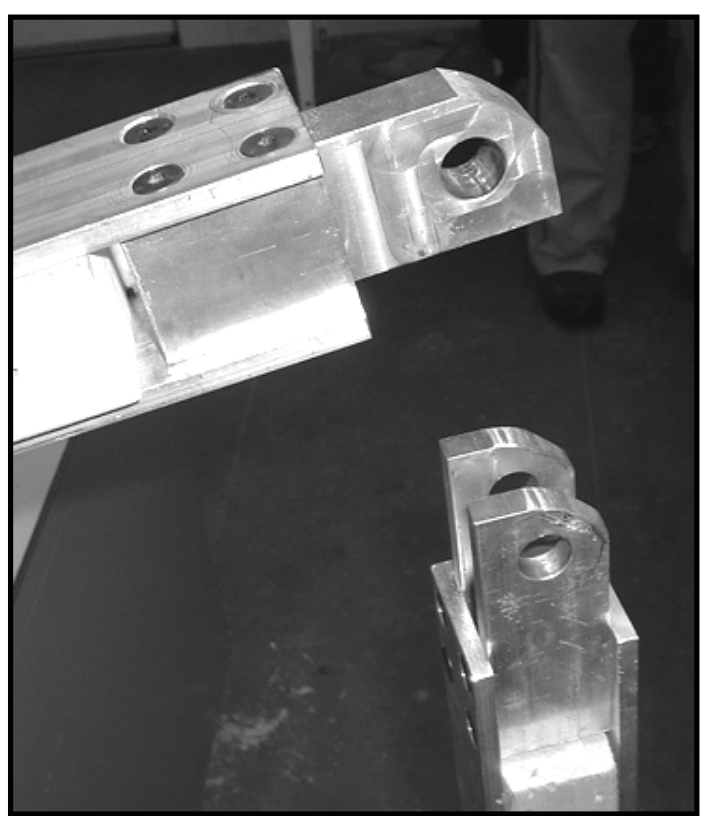

Fig. 2. Hinged corner connection of small-scale racking tester.

No standard is available for the small-scale racking test. The applied racking test procedures followed the general rules used when conducting the full-scale racking test standard. The staples used for the test were 16 gage, with a 1 inch crown and a 1 inch length. Staples were spaced at $7.62 \mathrm{~cm}$ (3in) intervals along the edges and at $15.24 \mathrm{~cm}$ (6in) to the middle stud. There were 8 or 4 staples applied at each side in $0.813 \mathrm{~m}$ (32in) or $0.406 \mathrm{~m}$ (16in) racking tests respectively, and 4 staples applied to the middle stud in $0.813 \mathrm{~m}$ (32in). The staple crown was perpendicular to shear stress direction on each side. Staples were centered on the wood stud. After one test, staples and sheathing were removed and stapling positions were shifted about $1.3 \mathrm{~cm}(0.5 \mathrm{in})$ along the stud for the next run. By shifting the staple location, four to six runs could be done before the studs were removed. The depth of wood inserts was $5.08 \mathrm{~cm}$ (2in) in the 32 -inch tester. This depth was double of staple leg length, which allowed for both surfaces of the wood inserts to be used before being discarded. The racking test loading speed was $2.54 \mathrm{~mm} / \mathrm{min}(0.1 \mathrm{in} / \mathrm{min})$, which was close to the load rate of $7901 \mathrm{~b}$ in $2 \mathrm{~min}$ specified in ASTM E72 (2).

To evaluate the buckling extent, out-of-plane displacement was measured using a combination-square and a reference bar clamped to the frame. When a measurement was made, the reference bar was attached to the backside of the tester frame and the combination-square was used to assure the scale was perpendicular to the original plane of the panel. The reference bar provided a reference plane that was parallel to the undeformed plane of the panel. The initial distance from the paperboard surface to the reference plane was measured prior to loading. The difference between the original distance and the distance measured while the tester was under load gave the amount of bulging in the panel at the point of measurement. To compare between samples, the measurements were made at prescribed diagonal displacements. When the extension was reached, the test was paused to hold the racking deformation constant. The measurement was taken at the center of the buckling region where it was a maximum. 


\section{Paperboard Staple Resistance Test}

During racking tests, cutting of the sheathing around the staples was observed. Therefore, the staple-cutting resistance of the paperboard was investigated and the staple resistance test shown in Fig. 3 was developed. The nature of this test is similar to the nail resistance test. Two paperboard strips having the same width of the studs $(3.81 \mathrm{~cm}$ (1.5in)) were aligned with a specimen of wood and stapled to the wood at opposite ends. The free ends of the paperboard were clamped to the jaws of an Instron 3344 series EM Test Instrument. The net paperboard length under tension (net gage length) was taken as the sum of the distances from the clamps to the middle of the staples for both paperboard samples. Different numbers of staples $(1,2$, or 3$)$ were used with the crown, either perpendicular, as illustrated in Fig. 3 (a), or parallel, as illustrated in Fig. 3 (b), to the load direction. Paperboard samples were cut in both the machine direction (MD) and the cross machine direction $(\mathrm{CD})$. A range of different gage lengths were used on the staple resistance tests.

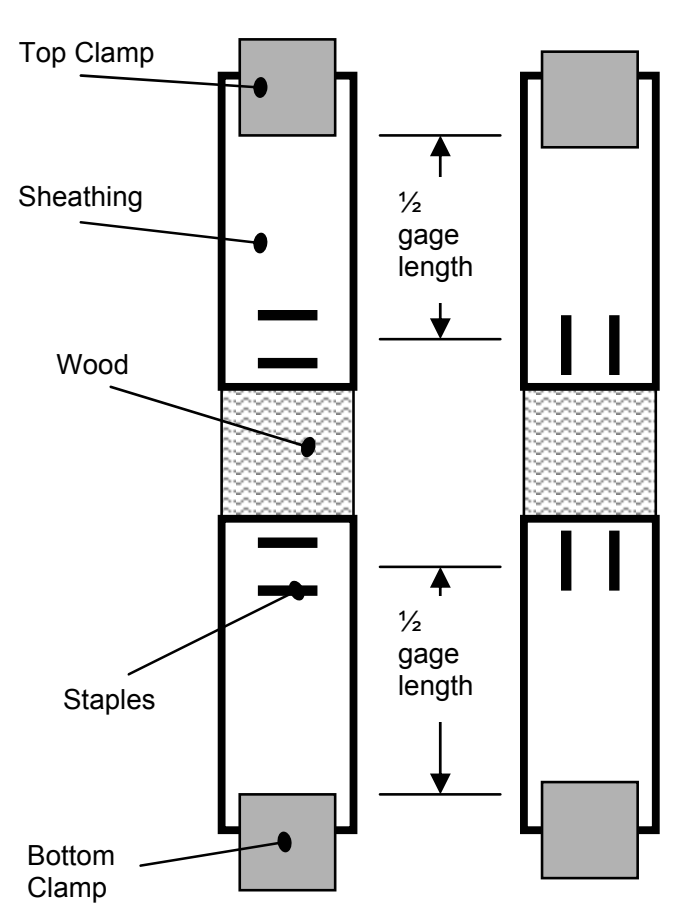

(a) (b)

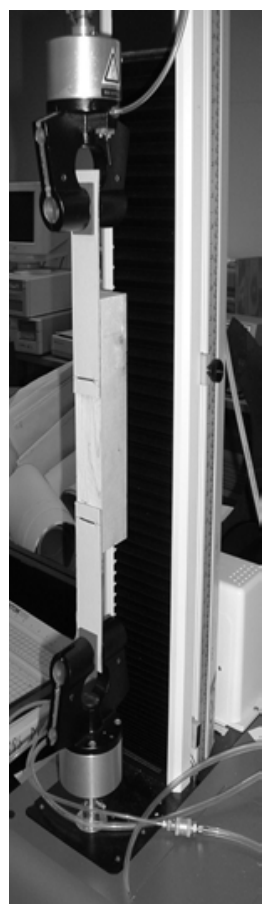

(c)

Fig. 3. Staple-resistance test. (a) Schematic with staples in perpendicular position, (b) Schematic with staples in parallel position, (c) Photo with one perpendicular staple.

\section{Techniques of Data Analysis}

The analysis of the load-deflection data merits discussion. Given the set-up described above, the load-deflection curve obtained from the racking tester is the diagonal elongation versus the diagonal force. When the test first begins, the whole frame is lifted, and any slack in the system is removed before the paper begins to deform. A typical load-deformation response from the racking test is shown in Fig. 4. This initial 
portion of the curve corresponds to lifting the frame off the bottom support. In the next region the load is fairly constant and corresponds to the pulling taut of the frame and the bottom clamp. The load level in the regime corresponds to the dead-load of the frame that had been supported by the bottom clamp. The final region where the load is increasing corresponds to the shear deformation of the sheathing. In the initial loading, there appears to be slack, that is probably due to the deformation needed to fully load the panel. To look at the shear-deformation of the panel, the dead-load and slack was removed. First, the dead load was subtracted from the total load to get the panel load. Next, the point of maximum slope was determined. The intercept of the tangent at the point of maximum slope with the axis of zero panel load were determined and taken as the point of zero-strain location. The corrected load-displacement curve used to determine racking load versus shear strain is shown as the curve shifted to the left in Fig. 4.

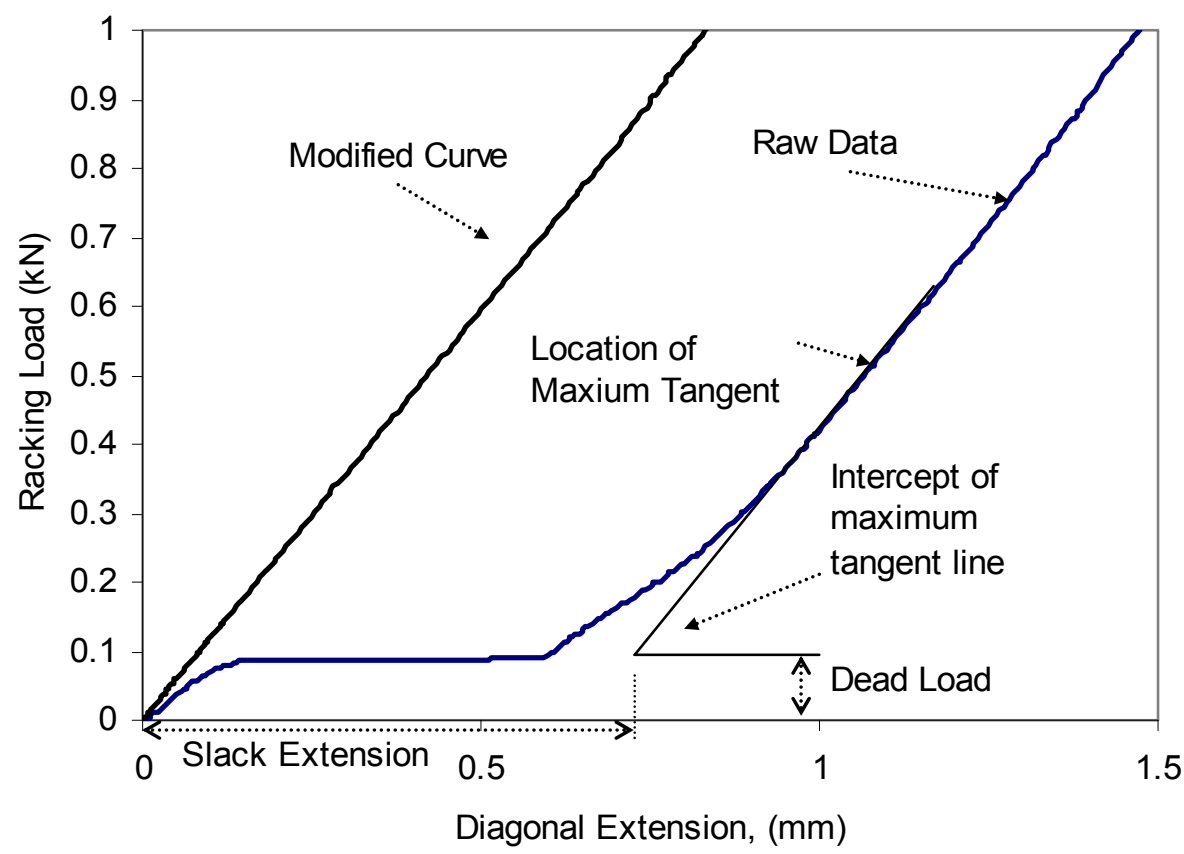

Fig. 4. Typical load-deformation curve before and after analysis.

The correction procedure described above was used to compare curves from different samples. Two other quantities were also taken for the purposes of comparison; racking strength and racking stiffness. Racking strength is the difference in maximum load and dead load divided by the length of the panel sides. The maximum load was not determined for all samples due to the limitation of the load cell, but for many of the samples a maximum was reached. The racking stiffness was determined as the maximum slope of the load versus elongation curve, determined from a running average on the slope versus elongation curve. The deformation interval used in the averaging corresponded to a shear strain of 0.0016 .

We define the racking stiffness as the initial slope of the load deformation curves. 


$$
K_{\text {racking }}=\frac{P}{\delta}
$$

To first order, the diagonal load, $P$, versus diagonal extension, $\delta$, can be directly related to the shear stress, $\tau$, and engineering shear strain, $\gamma$, in the panel as

$$
P=\sqrt{2} \text { at } \tau \quad \delta=\frac{a}{\sqrt{2}} \gamma
$$

where $a$ is the length of the sides of the panel and $t$ is the thickness of the panel. Assuming that the initial portion of the response can be described as linear-elastic, $\tau=G \gamma$ where $G$ is the shear modulus. For paper, the in-plane shear modulus has been experimentally found and reported to be proportional to the geometric mean of the normal moduli, $G=0.39 \sqrt{E_{M D} E_{C D}}$ (Baum et al. 1981). Substituting Eqn. (2) into Eqn. (1), along with the assumed elastic behavior, provides a prediction of the racking stiffness as

$$
K_{\text {racking }}=\frac{P}{\delta}=2 G t=0.78 \sqrt{E_{M D} E_{C D}} t
$$

According to Eqn. (3), $\mathrm{K}_{\text {racking }}$ is independent of the size of the test frame. For larger deformations of the panel, we expect the relationship of load to deformation to be nonlinear due to both buckling and yielding in the materials. The buckling will be length dependent, and therefore, scaling will not persist at larger deformations. With the current two test sizes the scaling of stiffness did hold. To check scaling of the load-deformation curve, the results were transformed to shear load and shear strain.

Results from the two-size testers are scaled using the shear strain and a racking shear load $\left(\mathrm{P}_{\text {shear }}=\tau \mathrm{t}\right)$. Thus, the resulting curves of load and deformation obtained from the racking tests are presented as $P_{\text {shear }}(\gamma)$ where

$$
P_{\text {shear }}=\frac{P}{\sqrt{2} a t \tau}, \gamma=\sqrt{2} \frac{\delta}{a}
$$

The initial stiffness of these scaled curves is $\frac{1}{2} K_{\text {racking }}$. For the board most prone to buckling (board A), the 32-inch panel results scaled with the 16-inch panel up to a shear strain of about $0.4 \%$. At larger shear strains, the 32-inch panel lost load capacity due to buckling. When a center stud was used in the 32-inch panel, the scaling persisted for the entire load path with strains up to $3 \%$. For the board least prone to buckling (board $\mathrm{C}$ ), the scaling was valid up to a strain of approximately $1 \%$.

Equation (3) gives an upper bound prediction for racking stiffness. The actual stiffness will be lower, because of the compliance in the fasteners and the frame. For the sheathing material, the factor of 0.78 shown in Eqn. (3) may not hold, because the approximation of Baum et al. (1981) was derived for uncoated paperboard. On the other hand, a linear correlation between geometric mean modulus and initial slope of the racking test was expected. 
If the load in the racking test peaks before the limit of the test system is reached, the maximum load is referred to as the racking strength.

\section{RESULTS AND DISCUSSION}

\section{Initial Racking Stiffness}

A series of racking tests of boards A, B and C were conducted, using both sizes of the racking testers, but without a middle stud. From the load-deflection data, the racking stiffness was calculated. A plot of racking stiffness versus geometric mean modulus is given in Fig. 5. The results indicate that a proportional relationship between geometric mean modulus and racking stiffness as suggested in Eqn. (3) exists. Since there was little difference in the values of geometric mean modulus for boards $\mathrm{B}$ and $\mathrm{C}$, there is not enough variation to give a robust test of the relationship, but it is encouraging that $\mathrm{B}$ and $\mathrm{C}$ have very similar racking stiffnesses and geometric mean moduli despite the large difference in grammage between the two sheets. There is very little difference in the racking stiffnesses for the two different size panels. The proportionality constant is only about 36 percent of the theoretical value given in Eqn. (3). A large portion of this difference is likely due to how well the load is transferred through the staples. Some of it could be due to viscoelastic effects or that the board has a lower shear modulus than the 0.39 value suggested by Baum et al (1981). The difference is not related to panel bulging, which is small in this range and would have caused the 32-inch panel to have a lower slope than the 16-inch panel.

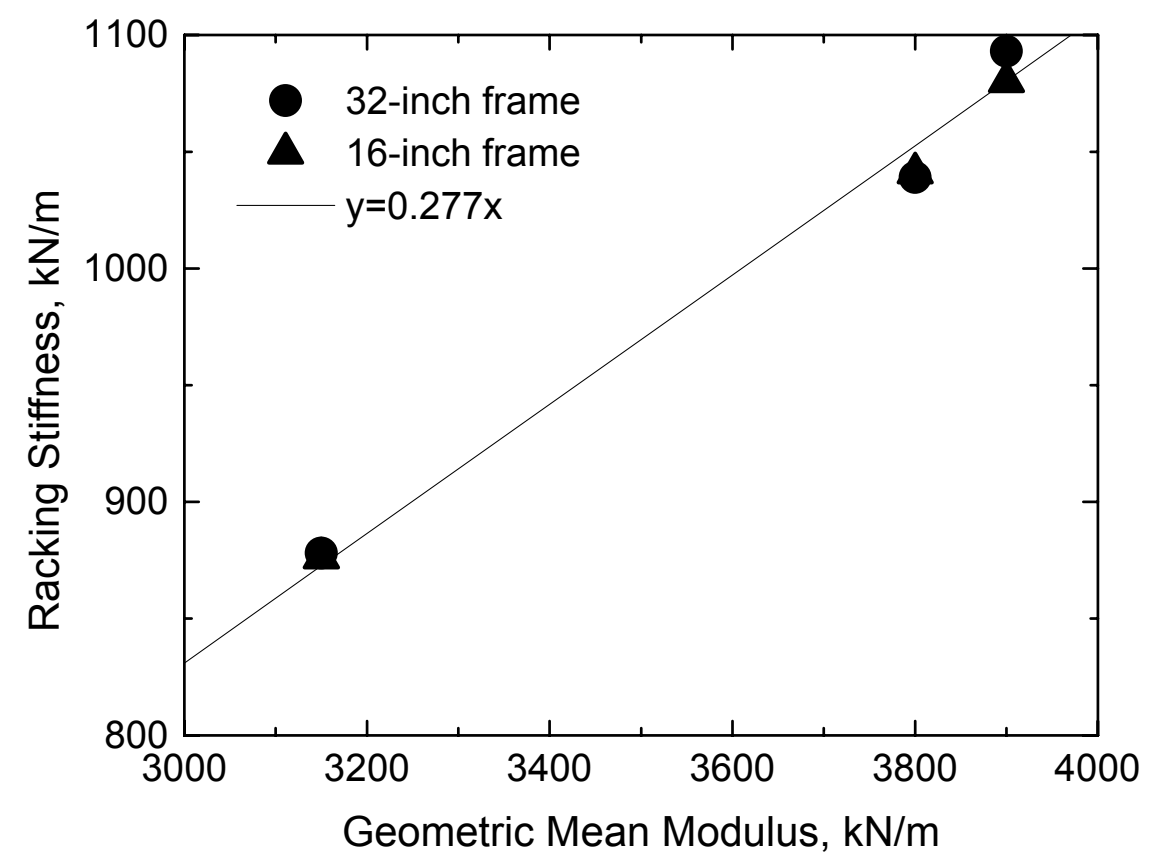

Fig. 5: Plot of racking stiffness against geometric mean modulus 


\section{Racking Strength}

Panel buckling was observed for all the racking tests conducted in this program. Buckling is resisted by higher bending stiffness and decreased span length. Buckling did not appear to influence racking stiffness, but can be expected to impact racking strength. If buckling impacts strength, one would expect that the 16-inch panels would obtain higher racking strengths than the 32-inch panels. In addition, adding the middle stud should reduce buckling and perhaps improve strength.

For paperboard A, racking strengths for tests which included the middle studs were about $20 \%$ higher than those tests that did not use the middle stud. This difference is shown in Fig. 6. For paperboard B, less racking strength differences were observed, however use of the middle stud improved racking strength. For board C, no differences were observed for loads up to the test limit of $4.45 \mathrm{KN}$ (1000lb) between tests with and without the middle stud. Paperboard A had the lowest caliper and hence lowest bending stiffness and Paperboard $\mathrm{C}$ had the highest bending stiffness. The results given in Fig. 6, suggest that buckling of the panel lowers racking strength.

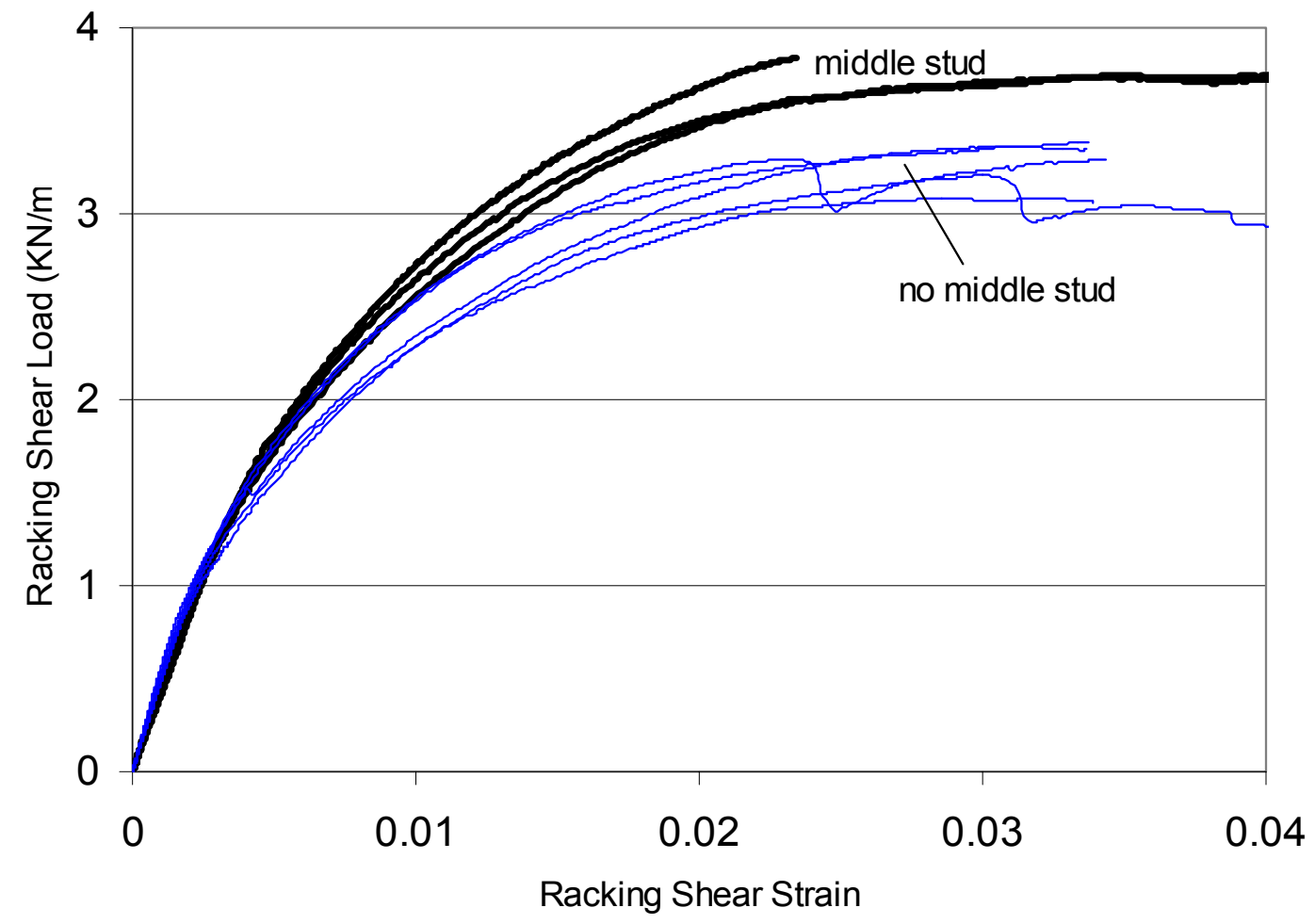

Fig. 6. Effect of middle stud on racking performance for Board A.

The racking strength differences for the three boards are clearly shown in Fig. 7 for both the 16-inch and 32-inch testing with no middle stud. The "V" shaped dips in load shown in the figures are due to stress relaxation that occurred when the deformation was held fixed while a buckling measurement was made. Buckling extents were measured at a net shear strain equal to 0.0106 and 0.0159. As expected, much larger buckling extents were observed for the 32-inch test (no middle stud) than those in 16-inch tests. For example, for board B the extent of buckling in the 32-inch test was $15 \mathrm{~mm}$ 
whereas it was only $1 \mathrm{~mm}$ in the 16-inch test. For the 16-inch test, board A had a bulge of $5 \mathrm{~mm}$, which is five times greater than that observed in B and C. Figure 7 also shows that for the 16-inch test boards $\mathrm{B}$ and $\mathrm{C}$ had similar responses except near the maximum loads where B was slightly weaker. This might be expected since the geometric mean modulus for both boards was quite similar and buckling was minimal. In the 32-inch test frame however, board $\mathrm{C}$ is stronger than $\mathrm{B}$ for a large range of strain. This is due to the extra buckling that occurs in the 32-inch test. Figure 7 clearly shows that the resistance to buckling offered in the 16-inch test frame leads to higher racking strength. These results combined with the differences in the tests with and without the middle stud and the observation that wrinkles traversed the middle stud during the test indicate that the current practice of spacing staples every 6 inches on middle studs does not provide sufficient resistance to buckling.

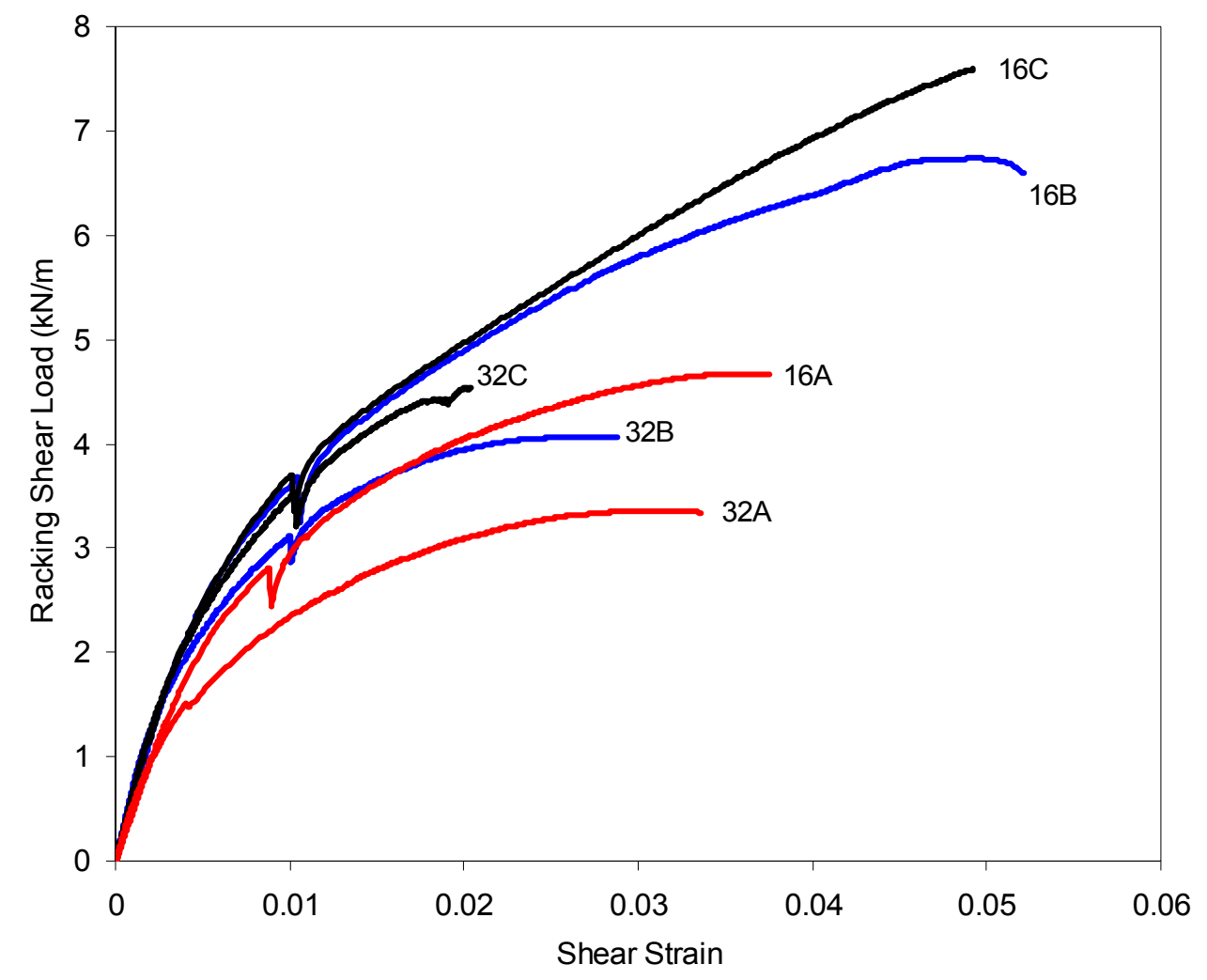

Fig. 7. Representative racking shear load versus shear strain curves of three paperboards without middle stud; 16 indicates 16 -inch test size, 32 indicates 32 -inch test size, A, B, C indicate board type.

\section{Staple Resistance}

Tensile load-strain curve of an MD sample of board A, along with the load-strain curves obtained from the staple resistance tests for three different MD gage lengths with either one, two or three staples are shown in Fig. 8. The staples were parallel to the load direction. The tensile tests and the staple resistance tests were conducted at the same loading speed (1in/min). 


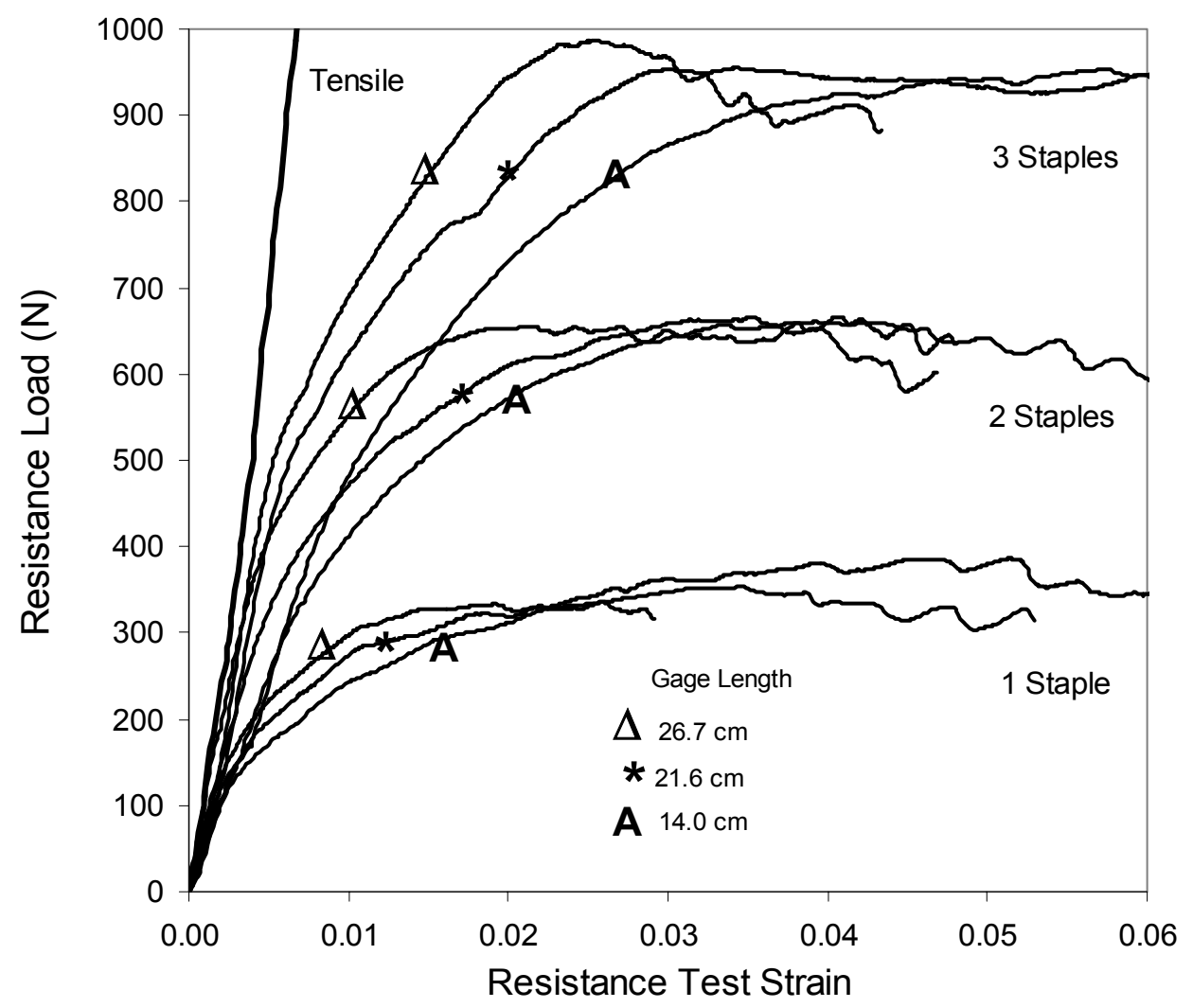

Fig. 8. Staple resistance test curves at varied net gage length and staple numbers

As the gage length increased in the staple-resistance test, the load-deformation curve approached that of the tensile test, but the maximum load did not increase. It appears that staple cutting influences the response even at fairly low load levels. The strength is approximately proportional to the number of staples, and therefore, one can estimate staple-resistance strength. In addition to increased gage length, increasing the number of staples also brought the stress-strain curve closer to that of the tensile test, but the maximum loads in the staple tests were much lower than that of the tensile test $(2220 \mathrm{~N})$. Therefore, staple cutting appears to severely limit strength and may even influence stiffness.

The maximum cutting forces for a series of staple tests using all three board types, MD and CD samples, and parallel and perpendicular staples were measured. Surprisingly, no significant differences were found between MD and CD samples. On the other hand, perpendicular staple orientation gave higher resistance loads than those with parallel orientation. This is probably due to additional resistance offered by the crown of the staple, which resists movement of the board when it is perpendicular to the load, but allows the paper to slip over the staple when it is parallel to the load.

In racking tests, paperboard (fiber) staple orientations were MD-Perpendicular on two sides and CD-Perpendicular on the other two sides. The staple-resistance strengths obtained from the tests presented in Fig. 8 are given in the second column of Table 2 . If we assume that the racking strength is limited by staple cutting, the average maximum 
staple cutting force $\left(\mathrm{P}_{\mathrm{S}}\right)$ from the staple resistance tests can be used to calculate the racking strength $\left(\mathrm{P}_{\mathrm{U}}\right)$ as follows:

$$
P_{U}=\sqrt{2} \times N \times P_{S}
$$

where, $\mathrm{N}$ : number of staples per side in racking tests, which was 8 for the 32 -inch test frame and 4 for the 16 -inch test frame.

Table 2: Comparison of actual and predicted racking strengths

\begin{tabular}{|c|c|c|c|c|c|}
\hline \multirow{2}{*}{$\begin{array}{l}\text { Paperboard } \\
\text { Grades }\end{array}$} & Nail Resistance, & \multicolumn{4}{|c|}{ Racking Strength, kN } \\
\cline { 3 - 6 } & N, From tests & \multicolumn{2}{|c|}{ 32-inch Test } & \multicolumn{2}{|c|}{ 16-inch Test } \\
\cline { 3 - 6 } & & Observed & Eqn. (5) & Observed & Eqn. (5) \\
\hline A & 400 & $3.56-4.14$ & 4.5 & $2.14-2.67$ & 2.3 \\
\hline B & 600 & 4.72 & 6.8 & $3.56-3.87$ & 3.4 \\
\hline C & 650 & 5.34 & 7.4 & $>4.45$ & 3.6 \\
\hline
\end{tabular}

The measured racking strengths, along with values calculated using Eqn. (3) are given in Table 2. For the 32-inch tests, the measured strengths are less than the calculated values. For the 16-inch tests, the test values are greater than the predicted values. This can be interpreted as follows, the deformation on the frame results in shear deformation, panel buckling, and/or staple cutting. Our observations indicate that the larger the extent of buckling, the lower the degree of paperboard cutting by staples, and vise-versa. In the smaller panel tests, buckling was low, staple cutting was high, and the strength is probably dominated by staple-cutting resistance. In the larger panels, the buckling was much greater, and strength was lower than that due to staple cutting alone. This result also suggests that buckling must have a significant impact on racking strength in the larger panels.

\section{Non-uniform Shear Stress Transfer and Cutting Due to Staples}

The predicted initial slopes of three paperboards calculated by Eqn. (3) were 2450, 2950 and $3050 \mathrm{KN} / \mathrm{m}$ for paperboards A, B and C, respectively. These values were almost triple that of the observed initial slopes. These predicted initial stiffnesses assume uniform and infinitely stiff connections along the sheathing edges. In fact, the shear stress transfer to paperboards occurs only through the staples, and stress concentrations can be expected to impact racking stiffness and strength.

To provide a more uniform shear stress transfer, additional staples were applied to each edge for a sample of board $\mathrm{C}$ in the 32-inch tester. Figure 9 provides stress-strain curves of a sample that was loaded and unloaded several times. Each time the sample was unloaded more staples were added to the edges. The results show that adding more staples increased the racking stiffness. The racking stiffness values increased by 15 and 50 percent when using twice and five-times the original number of staples $(8 /$ side) respectively. 


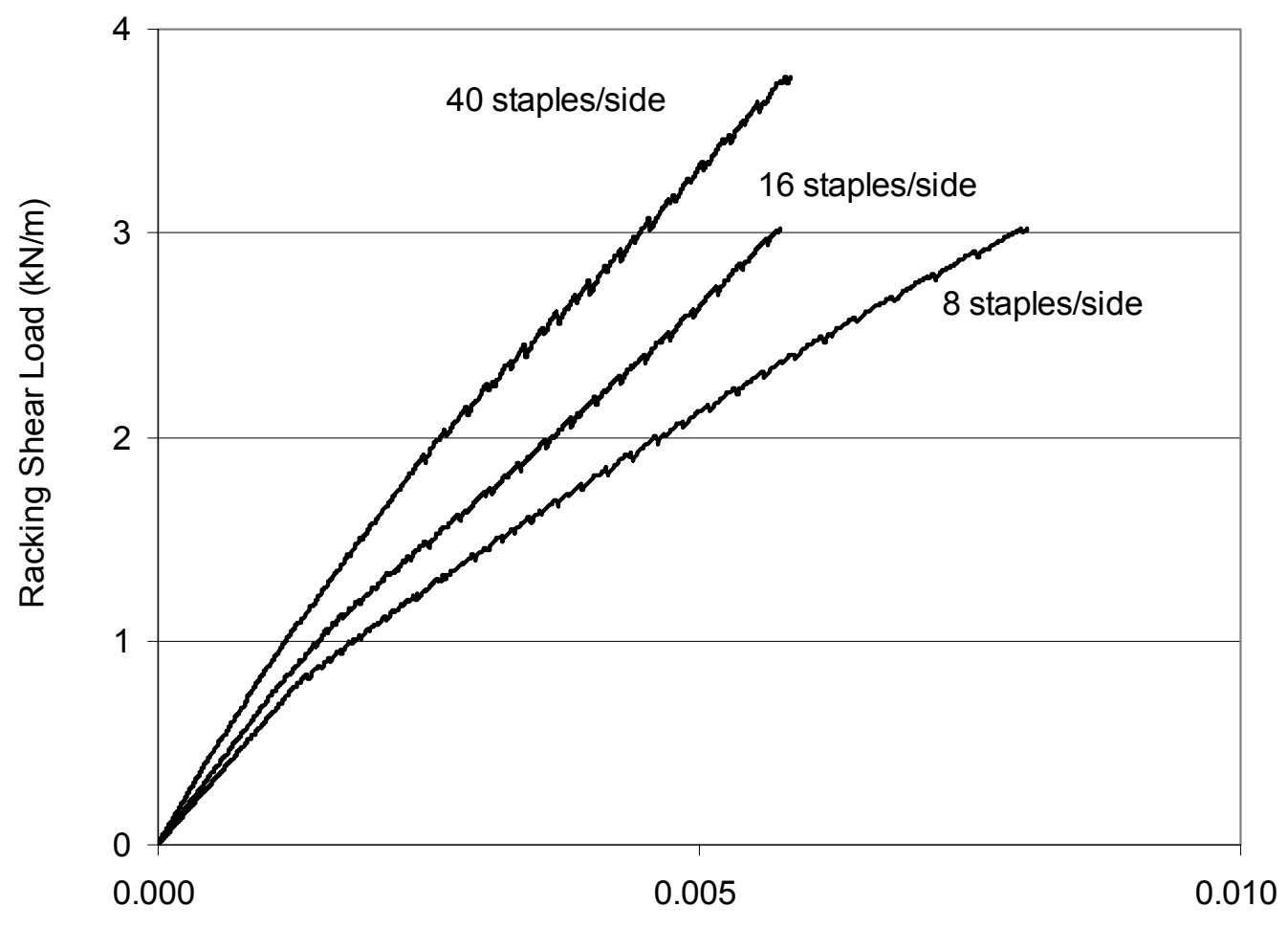

Racking Shear Strain

Fig. 9. Racking curves with increased number of staples for the $0.813 \mathrm{~m}$ (32in) tests with board C

To provide a very uniform sheathing connection the panel was glued to the test frame using Liquid Nail glue with the 16-inch tester. A comparison of the racking response using staples and that using glue are shown for board A in Fig. 10. Clearly the gluing method provided superior racking stiffness and racking strength with a 40-50\% increase in racking strength and about a 50\% increase in racking stiffness for paperboard A. The average values of buckling extents and initial slopes (average-type) are compared for the two methods in Table 3. The glue test with board B failed quite early and paperboard was peeled away from tester frame at one corner due to the weak gluing at that location. Buckling was not measured for board B. With glued panels, the extra compliance from staple cutting was absent and the extent of buckling was slightly larger than those in the staple tests. Initial racking stiffness values from glue panels were about $50 \%$ higher than those from stapled panels for all three paperboards. 


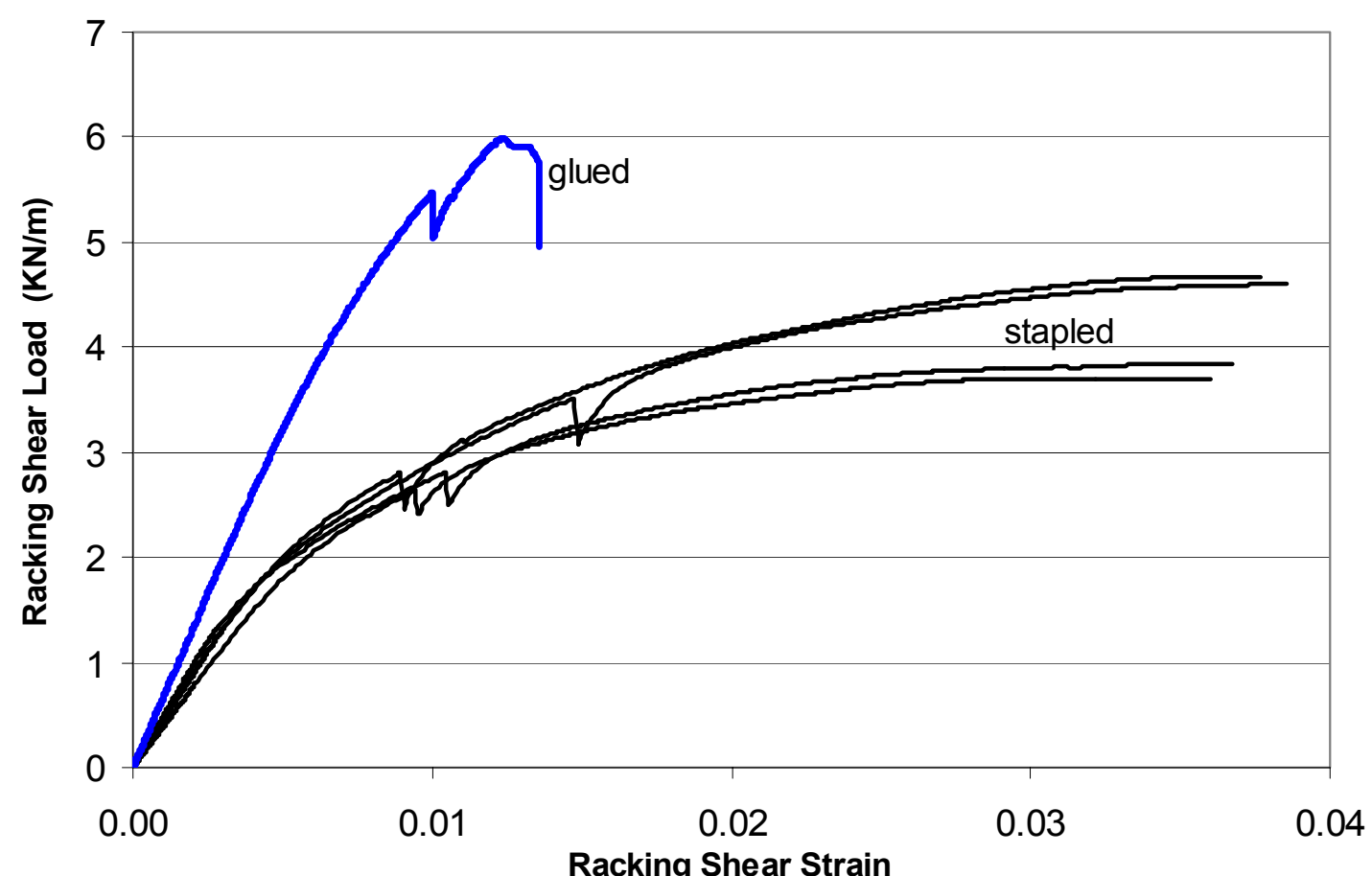

Fig. 10. Comparisons of racking responses between glue and stapling the sheathing for the 16inch tests of board $A$

Table 3: Comparisons of initial slopes and extent of buckling using different methods to attach sheathing in 16-inch racking tests

\begin{tabular}{|l|c|c|c|c|}
\hline \multirow{2}{*}{ Paperboard Grade } & \multicolumn{2}{|c|}{ Extent of Buckling $(\mathrm{mm})$} & \multicolumn{2}{c|}{ Racking Stiffness (KN/m) } \\
\cline { 2 - 5 } & Glue & Staple & Glue & Staple \\
\hline A & 7.1 & 5.3 & 1315 & 876 \\
\hline B & N/A & 1.0 & 1462 & 1041 \\
\hline C & 1.0 & 1.0 & 1581 & 1080 \\
\hline
\end{tabular}

\section{CONCLUSIONS}

A small-scale racking tester was developed to evaluate paperboard sheathing materials. It appears that the tester is useful to evaluate racking performance of both the paperboard and the fasteners. The tester provides an economical alternative to the fullscale racking test when one is interested in evaluating differences in sheathing materials. Based on the results and discussions presented above, we conclude the following:

1. The geometric mean modulus multiplied by caliper provides a predictor for racking stiffness.

2. Racking stiffness was unaffected by buckling, test dimension changes, and paperboard $\mathrm{MD} / \mathrm{CD}$ orientation.

3. Racking stiffness was affected by the number of staples. Lower magnitudes of the observed initial stiffness values were mainly caused by non-uniform shear stress transfer if using staples. 
4. Racking strength is negatively affected by both panel buckling and the staple method used to attach the sheathing to the studs.

5. Racking strength could be greatly improved by reducing buckling extents, using thicker boards or gluing the board to the studs.

Given that gluing is probably not acceptable to many home builders, the producer of the sheathing must determine methods to increase fastener resistance of the board. The small-scale tester is probably not sufficient to capture the differences that may be caused by changing the MD/CD orientation of the board with respect to the framing. This is due to the aspect ratio of free spans in 32-inch test with studs is only two while in the real wall is six. In a real wall system, mounting the sheathing so that MD is perpendicular to the framing studs may give higher racking strength.

In summary, the small scale racking test could differentiate differences in the three board types. The small-sale racking tester, along with the staple resistance tester provides alternative methods to evaluate potential sheathing materials before full-scale tests are completed.

\section{ACKNOWLEDGMENTS}

This work was completed in partial fulfillment of an MS degree from Miami University. The authors express sincere gratitude to Mr. Rodney Kolb for his participation and to Fibre Converters (Constantine, MI) for providing the paperboard.

\section{REFERENCES CITED}

Baum, G. A., Brennan, D. G., and Habeger, C. C. (1981). "Orthotropic elastic constants of paper," Tappi J. 64(8), 97-101.

McCutcheon, W. J. (1985). "Racking deformations in wood shear walls," J. Struc. Eng. 111(2), 257-269.

Neisel, R. H. (1958). "Racking strength and lateral nail resistance of fiberboard sheathing," Tappi J. 41(12), 735-737.

Neisel, R. H. and Guerrera, J. F. (1956). "Racking strength of fiberboard sheathing," Tappi J. 39(9), 625-628.

Patton-Mallory, M., Wolfe, R. W., Soltis, L. A., and Gutkowski, R. M. (1985). "Lightframe shear wall length and opening effects," J. Struc. Eng. 111(10), 2227-2239.

Price, E. W., and Gromala, D. S. (1980). "Racking strength of walls sheathed with structural flakeboards made from southern species," Forest Prod. J. 30(12), 19-23.

Sherwood, G., and Moody, R. C. (1989). "Light-frame wall and floor system: Analysis and performance. General Technical Report FPL-GTR-59," USDA Forest Serv. Forest Prod. Lab., Madison, WI.

Tuomi, R. L., and Gromala, D. S., 1977. "Racking strength of walls: Let-in corner bracing, sheet materials, and the effect of loading rate," U.S. Dept. Agric. Forest Serv. Res. Pap. FPL 301. 20p. 
Welsch, G. J. (1963). "Racking strength of half-inch fiberboard sheathings," Tappi J. 46(8), 456-458.

\section{STANDARDS CITED}

American Society for Testing and Materials. (1997). Test Methods for Evaluating Properties of Wood-Based Fiber and Particle Panel Materials. ASTM D1037. Philadelphia, PA.

American Society for Testing and Materials. (1997). Standard Test Methods of Conducting Strength Tests of Panels for Building Construction. ASTM E72. Philadelphia, PA.

TAPPI. (1983). Racking Strength of Structural Insulating Board. T1005 cm-83. Atlanta, GA

Article submitted: November 5, 2006; Reviews completed Dec. 11, 2006; Revised article accepted Dec. 15, 2006; Article published Dec. 18, 2006. 